\title{
Over-Expression of GH/GHR in Breast Cancer and Oncosuppressor Role of Somatostatin as a Physiological Inhibitor
}

\section{Giuseppe Di Bella ${ }^{1}$, Roberta Scanferlato ${ }^{1}$ and Biagio Colori ${ }^{2}$}

${ }^{1}$ Di Bella Foundation, Via Guglielmo Marconi 51 Bologna, Italy

${ }^{2}$ Rizzoli Scientific Research and Care Institute, Via Giulio Cesare Pupilli, Bologna, Italy

${ }^{*}$ Corresponding author: Dr. Giuseppe Di Bella, Di Bella Foundation Via Marconi 51, Post code 40122, Bologna, Italy, Tel: +39 $051239662 ;+39$ 051 230369; E-mail: posta@giuseppedibella.it

Rec date: May 23, 2018; Acc date: July 24, 2018; Pub date: July 30, 2018

Citation: Bella GD, Scanferlato R, Colori B (2018) Over-Expression of GH/GHR in Breast Cancer and Oncosuppressor Role of Somatostatin as a Physiological Inhibitor. Transl Biomed. Vol.9 No.3:151

\section{Abstract}

Background: The interaction between pituitary hormones (Growth Hormone-Prolactin), ovarian hormones (Estradiol) and growth factors forms the basis of the mechanisms underlying the growth of tumors of the breast. The literature contains reports of the increased expression of the mitogenic GH (Growth Hormone)/IGF1 (Insulin-Like Growth Factor) axis in tumor tissues compared to healthy tissues, with a directly proportional dose-dependent relationship between GH/IGF1, proliferative index and invasive ability in numerous types of tumors.

Methods and Findings: We carried out this experimental research on the mitogenic role of $\mathrm{GH}$ and consequently on the rationale of the anticancer use of its inhibition. The levels of expression of several genes, GH and GHR, were evaluated in 39 cases of breast cancer, divided according to different risk levels on the basis of immunohistochemical and histological tests with nuclear grade.

Conclusion: Research showed that breast cancers with a high and intermediate risk of recurrence are characterized by over-expression of $\mathrm{GH}$ and of its receptor (GHR). The expression was limited in cases with a low risk. The overexpression of GH-GHR in breast cancer with a ratio proportional to the level of aggressiveness is a rationale that can encourage a therapeutic intervention with inhibition of the mitogenic GH-IGF1-PRL axis and estrogen.

Keywords: Growth hormone; Somatostatine; Breast cancer; Mitogenic axis; Growth factor

\section{Introduction}

It has been scientifically proven with endocrine, biological and biochemical data [1,2] that the physiological growth mammary glands is stimulated by anterior pituitary hormone
$\mathrm{GH}$, prolactin (Figure 1) and estrogen ovarian hormones [3], with the contribution of $\mathrm{GH}$-correlated growth factors, including IGF1 (Insulin-like Growth Factor), VEGF-A (Vascular Endothelial Growth Factor-A), and EGF (Epidermal Growth Factor). The master regulators of breast development are the steroid hormones, estrogen and progesterone, growth hormone $(\mathrm{GH})$, mostly via its secretory product, insulin-like growth factor 1 (IGF-1), and prolactin [4]. Estrogen and GH are essential for breast development at puberty; prolactin stimulates the mammary glands to produce milk.

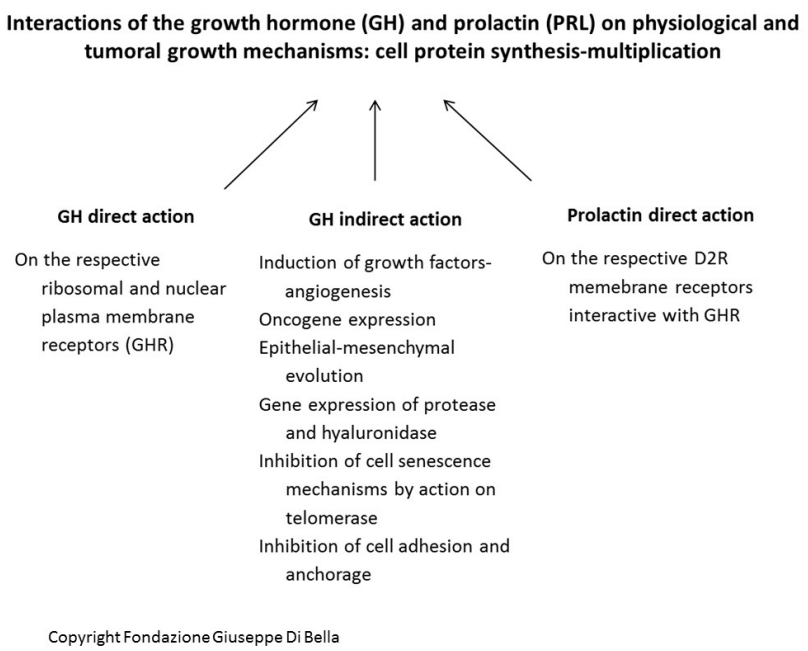

Figure 1 Cooperation between direct and indirect actions of $\mathrm{GH}$ and prolactin on physiological pathway and tumour induction.

$\mathrm{GH}$ is a peptide hormone, synthesized, accumulated and secreted by the adenohypophysis. The numerous functions carried out by $\mathrm{GH}$ include regulation of body growth, cell proliferation and differentiation and regulation of the metabolism of proteins, lipids and carbohydrates [5]. GH also causes an increase in protein synthesis in cells with multiple 
mechanisms including: activation of some carriers of plasma membrane amino acids, causing increased entry into the cytoplasm, transduction of cellular mRNA even without a greater than normal concentration of amino acids, and an increase of protein synthesis by ribosomes.

$\mathrm{GH}$ is the main mediator of the postnatal growth of somatic cells and its effects on cell growth and differentiation are mediated through interaction with its receptor (GHR) [5] which activates signal transduction pathways critical for cell growth and survival, including the transducers of the Janus kinase 2 signal with phosphorylation of the transcription factors (JAK-2) STAT), the cascade of the mitogen-activated protein kinase (kinase MAP P44/42), and of the phosphoinositide 3-kinase (PI3K) [5,6] (Figures 2 and 3).

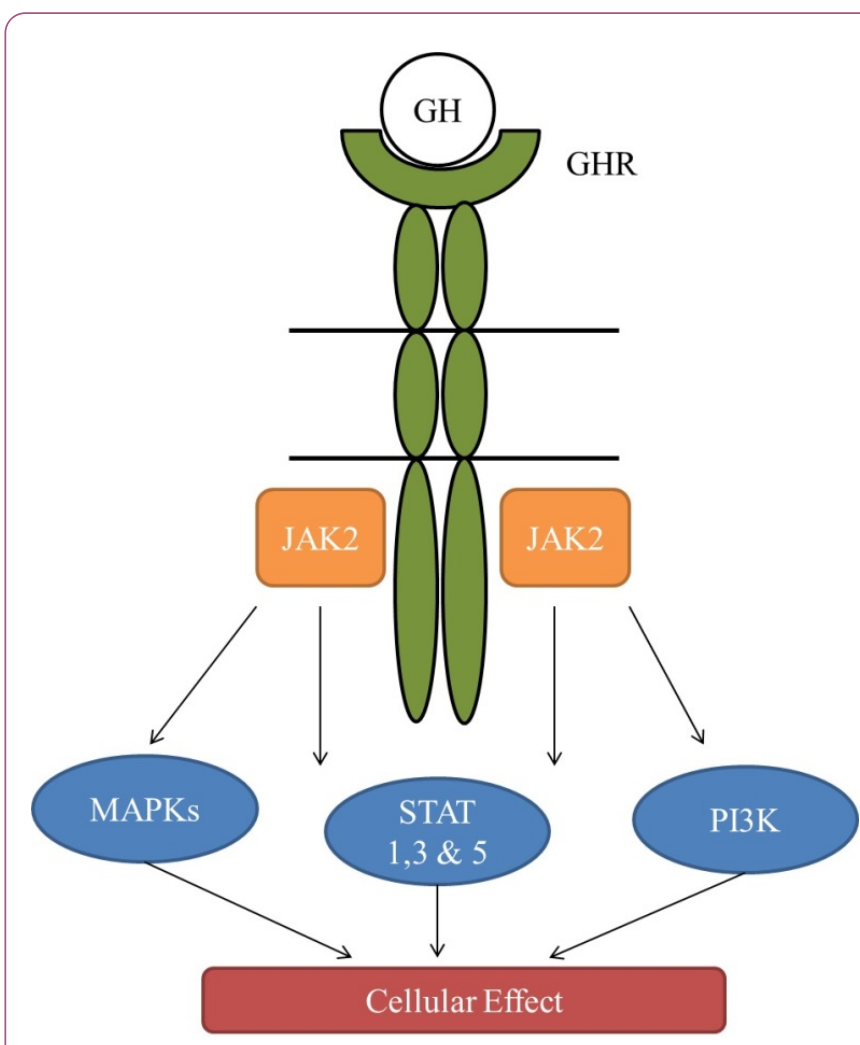

Figure 2 Transduction signal of GH-GHR interaction.

The family of cytokine receptors (Class I) and the family of interferon receptors (Class II) share structural characteristics and common signal transduction pathways with GHR. In fact, both classes of receptor are associated with various members of the family of Janus tyrosine kinases (JAK) and activate a new family of transcription factors, known as transcription transducers and activators, which relate ligands to activation of gene expression [7].

To understand the actions of $\mathrm{GH}$ it is necessary to know the structure and expression of its receptor. The cloning and sequencing of the $\mathrm{GH}$ receptor showed that this receptor exhibit considerable structural homology (as well as exerting similar biological effects) with prolactin receptor. A widespread distribution of variable concentrations of GHR was observed in many types of normal and tumor cells, with a marked and significant prevalence in tumor cells; this prevalence is in proportion to the proliferative index and to the invasive and metastasizing ability [8].

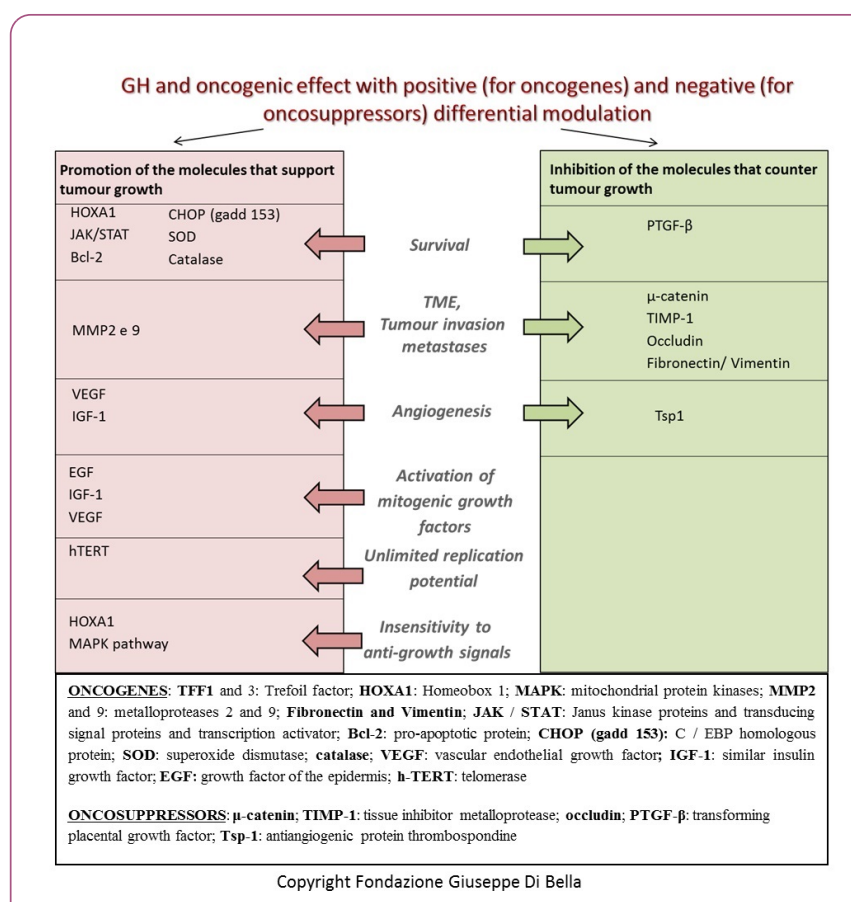

Figure 3 Growth hormone interacts with many genes (oncogenes and oncosuppressors) that are part of growth different mechanism. At the middle of image (survival, TME, angiogenesis) different mechanism of growth; in red factors and enzymes that are promoted by GH to induce tumour; in green factors that are inhibited by $\mathrm{GH}$.

GHRs have been found on the cell surfaces of many tissues throughout the body; although most GHRs reside on the cell surface and in the endoplasmic reticulum, pronounced nuclear localization is noted in many cells [9]. In general, the expression of GHR can be detected with various immunohistochemical, molecular, western blot, and scintigraphy techniques, etc. The cytoplasmic synthesis of GHR has also been demonstrated at the level of the endoplasmic reticulum and the Golgi apparatus [10]. It was shown that the $\mathrm{GH}$ in the serum circulates complexed with GHBP (Growth Hormone-Binding Protein) [11,12]. Human serum GHBP contains the extra cellular portion of GHR and can be produced by a specific proteolytic cleavage of the extra-cellular domain of GHR [13]. The extracellular protein portion that binds the hormone is therefore common to GHR and GHBP. The nuclear receptor also has the same protein portion that binds the $\mathrm{GH}$ present in both GHR and GHBP [14]. The presence of GHR in the nucleus suggests that the $\mathrm{GH}$ internalized in the cell can modulate the transcription of specific genes. A direct effect of $\mathrm{GH}$ in the gene expression is highly probable. The GHR shares two properties of the proto-oncogenes:

- The untranslated $5^{\prime}$ region of the cDNA of the receptor is significantly longer than average

- GH has two start sites of transcription upstream of the translation start site. 
Both characteristics are present in mRNA which encodes for proto-oncogenes.

The expression of the IGF-1 gene is regulated differently by the GH in different tissues [15]. The dependence of IGF-1 on $\mathrm{GH}$ has been extensively confirmed in humans. In patients with complete GH deficiency, the levels of IGF-1 are always decreased, with the lowest levels found in patients with Laron dwarfism in whom the GHR is missing [16]. The administration of $\mathrm{GH}$ causes an increase of IGF-1 in GH-responsive patients. However, the co-localization of IGF-1 and GHR is not necessary since the role of $\mathrm{GH}$ in the tumor cells may be to regulate the function of the mature cells rather than to promote cell proliferation by local synthesis of IGF-1. These two molecules do not always act in harmony; in some tissues the synthesis of IGF-1 is independent of GH [17], despite the fact that these tissues possess GHR, as shown by a powerful mitogenesis independent of IGF-1 in response to GH [18]. More in-depth studies are required to establish whether, and in what conditions and in which tissues $\mathrm{GH}$ can act independently of the synthesis of IGF-1 in human tumor cells.

The literature contains scientific evidence relative to the mitogenic, biochemical and molecular mechanisms of action of $\mathrm{GH}$ and $\mathrm{GH}$-correlated growth factors. In the case of breast cancer, human recombinant $\mathrm{GH}$ increases tumor cell proliferation [1], increases the activity of telomerase favoring cell immortalization [19-21] and metastasizing of breast cancer by interruption of the cell-cell contact and increase in cell migration and invasion [22]. In addition, the GH-IGF-1 axis is over-expressed in breast cancer compared to adjacent healthy tissue $[23,24]$. There is also a considerable amount of evidence for other types of tumor, for example multiple myelomas [25] and bone tumors $[26,27]$ in which $\mathrm{GH}$ accelerates the growth and has been found at high levels of concentration. The expression of its receptor, GHR, is found in greater concentrations in tumor cells [8]. GH activates numerous genes of angiogenic inductors (eNOS - endothelial Nitric Oxide synthesis, VEGF and bFGF - basic Fibroblast Growth Factor) and migration of endothelial cells [28,29]. In general, GH significantly increases the expression of the proto-oncogene cmyc [30].

These data confirm that, in addition to playing a vital role in somatic cell growth, the GH/IGF1 axis has a cancerogenous effect, interacting with prolactin (Figure 4) and estrogens (quaternary proliferative GH/IGF1/PRL/ER axis) in breast cancer formation [31]. We believe it is useful to repeat and stress the fact that most of the mitogenic effects of $\mathrm{GH}$ in somatic cells are mediated not only by hepatic IGF-1 1 but also by induction of the expression of other growth factors such as EGF [32] and VEGF-A [33], GH-correlated.

The GH/IGF-1 axis also modulates the immune system, although the way in which this interaction takes place and the proportional relationships have not been clarified. GH directly regulates the function of the lymphocytes through its receptor [34], or with an action mediated by IGF-1 [35]. The increase of GHR in melanocytes, nevi, primary melanomas and metastatic melanomas is evidence of its activation of the tumor progression in these diseases. The expression of GHR in benign prostate hyperplasia and in carcinoma of the prostate is proportional to the aggressiveness and proliferative index of these cell clones [36-38].

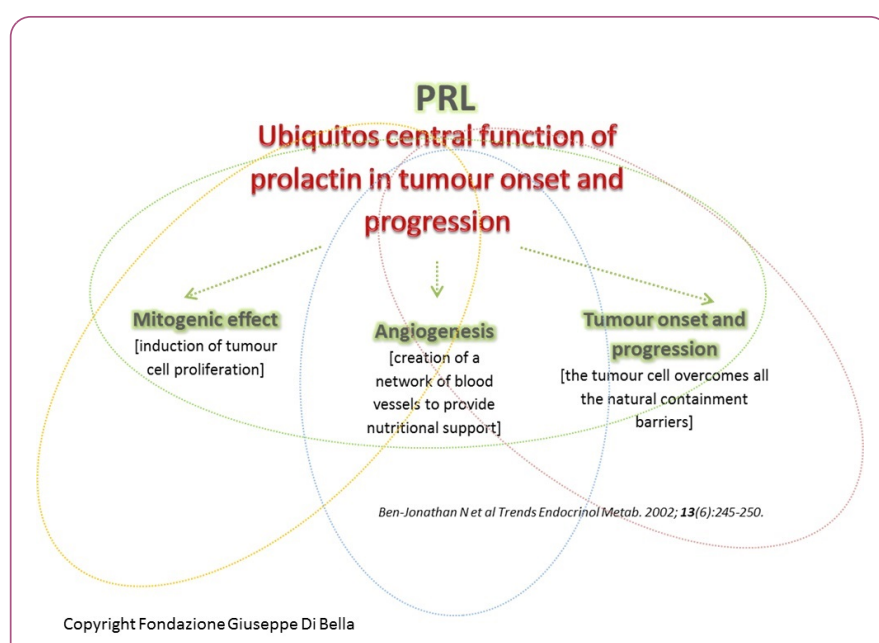

Figure 4 Prolactin has a central role in tumour onset and progression through mitogenic effect and angiogenesis also.

To experimentally confirm and make clinical use of these scientific data, the non-for-profit Giuseppe Di Bella Foundation (set up for medical-scientific research) designed a research project for the expression of GH and GHR in breast cancer cell clones. The study was also designed to detect the positive relationship of, and any dose-dependent relationship between concentration of $\mathrm{GH}, \mathrm{GHR}$, aggressiveness, proliferation index, resistance and metastasizing, thus ascertaining the rationality and the scientific grounds for the use of the physiological inhibitor of $\mathrm{GH}$, somatostatin and analogues. The aim of this project was to test the expression of a set of genes correlated with the pathway of $\mathrm{GH}$ by means of protocols of real-time quantitative PCR, starting from formalin fixed and paraffin embedded human tissues.

\section{Materials and Methods}

\section{Study of the expression of $\mathrm{GH}$ and its receptor in breast cancer}

39 cases of breast cancer (average age of the study group 55 years) were examined using the facilities of the Institute of Pathological Anatomy of the University of Bologna, dividing them according to different risk levels on the basis of immunohistochemical and histological tests with nuclear grade: "High Risk" Ki67 $\geq 50 \%$ " (Nuclear grade G3) (20 cases), "Intermediate Risk" 10\%>Ki67>40\% (G2) (13 cases) and "Low Risk" Ki67<10\% (G1) (6 cases). In all cases, the mRNA of 18 genes was analyzed: GHR, GH1, TFF3, IGF1, BCL2, GHRH, GHRHR, HGF, HOXA1, KI67, PDGFA, PRL, PRLR, VEGFA, SERF1, FGF18, PRC1, MMP9. The ACTB and B2M genes were used as housekeeping genes. This study was conducted in accordance with the ethical principles that have their origins in the Declaration of Helsinki. All subjects of the study gave their 
informed consent for anonymous data treatment according to the privacy rules.

RNA was then extracted from $420 \mu \mathrm{m}$ slices of formalin fixed and paraffin embedded tissue. Briefly, after paraffin processing by clearing in xylol and ethanol, the sample was extracted using the High Pure miRNA Isolation Kit (Roche Applied Science) and eluted in $50 \mu$ of Elution Buffer.

The extracted RNA was then retro transcribed by means of the Transcriptor High Fidelity cDNA Synthesis Kit (Roche Applied Science) and the cDNA that was obtained was analyzed by means of Real-Time qPCR. The primers were designed using Primer 3, repeatmasker, Mfold, and PrimerBlast software. A gene was considered up-regulated with a foldchange $(F C)>2$, and down-regulated with $F C<-2$. The results were analyzed by means of Data Assist v 3. 01.

\section{Results}

On the basis of this study, the cases classified as "High Risk" and "Intermediate Risk" show over-expression (FC>2) of GH and GHR compared to the samples classified as "Low Risk". The GHRH gene, on the other hand, was down-regulated $(F C<-2)$ in the "High Risk" and "Intermediate Risk" groups (Figures 5 and 6).
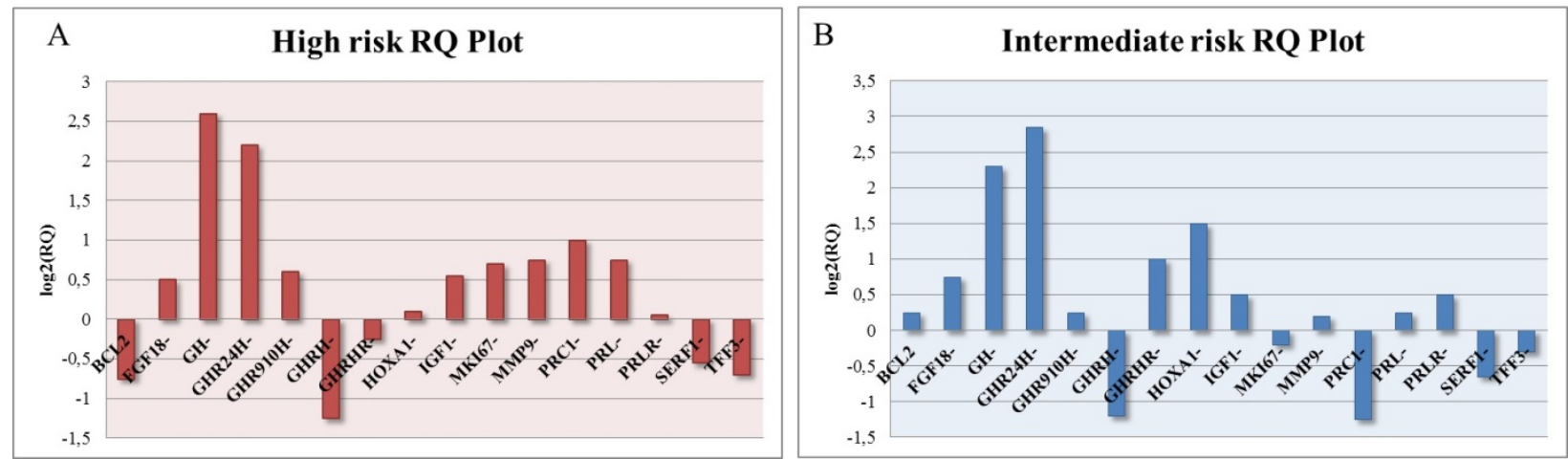

Figure 5 Profile of expression of the cases of breast cancer analyzed in the "High Risk" (A) and "Intermediate Risk" (B) groups.

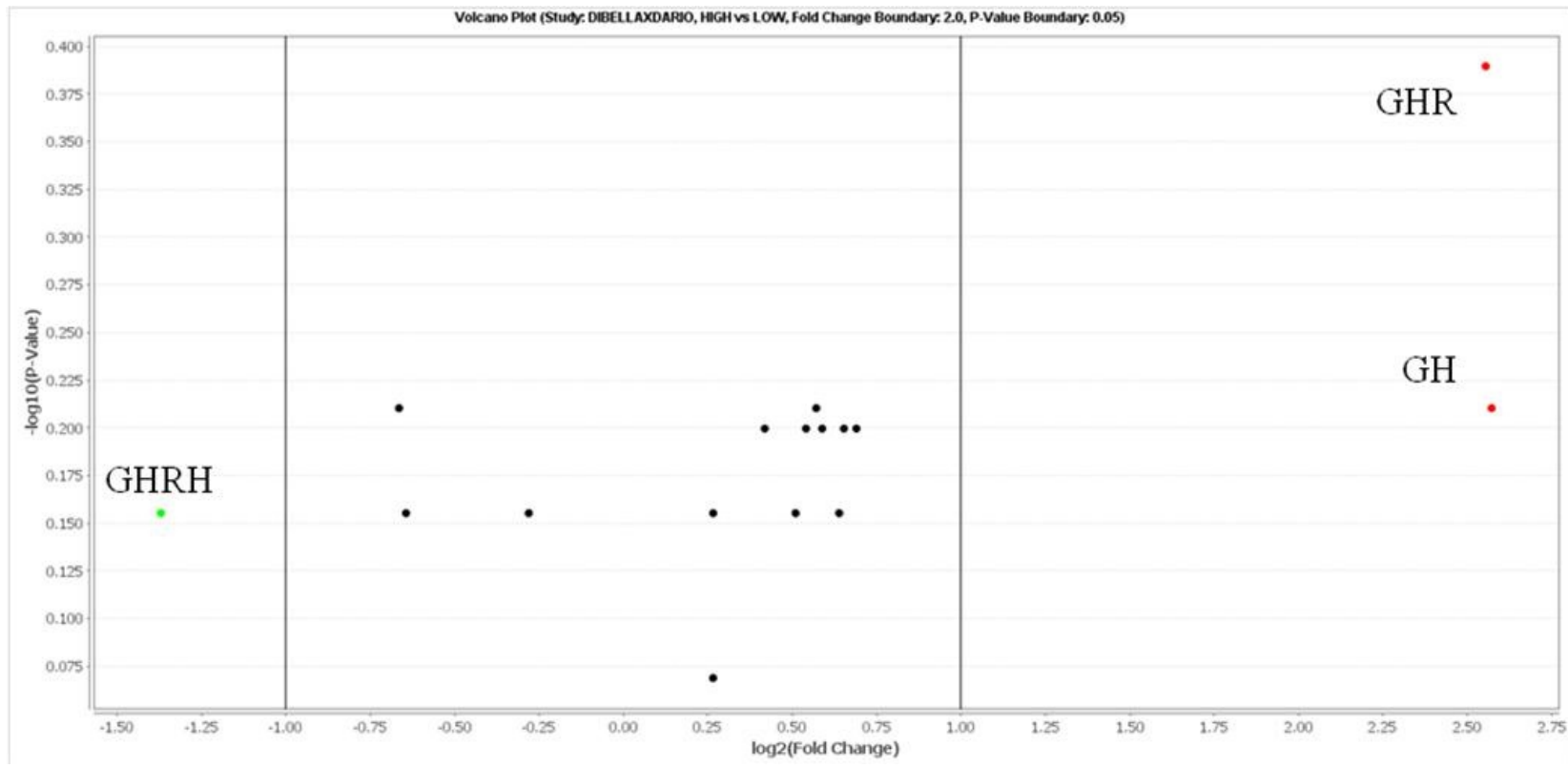

Figure 6 Volcano plot showing the over-expression of GH and GHR (red dots) and the down-regulation of GHRH (green dot) in the "High Risk" and "Intermediate Risk" groups.

The same result was observed when the "High Risk" and "Intermediate Risk" groups were considered together and compared with the expression values of the "Low Risk" group (Figure 7). GH and GHR were up-regulated (with respective FC values of 5.95 and 5.88 times), while GHRH è was downregulated $(\mathrm{FC}=-2.58)$. 


\section{Discussion}

The study described herein is a preliminary analysis, that firstly gave confirmation of the data reported in the literature regarding the systematic over-expression of GH, IGF1, and GHR, which is present not only in breast cancer, but in many even histologically different forms of cancer. These experimental and clinical data, consistent with the biological function of $\mathrm{GH}$, provide further confirmation of the oncogenic induction of its over-expression and the dose-dependent relationship between the extent of the GH/IGF1/GHR expression and the proliferative and aggressive characteristics of the tumor clones [39]. Through the differential regulation of the gene expression, autocrine $\mathrm{GH}$ also regulates vital molecular and biochemical mechanisms such as cell growth and survival, migration and invasion, epithelial-mesenchymal transition (EMT), replication potential and oncogenic transformation. The genes that autocrine $\mathrm{GH}$ regulates positively or negatively to induce oncogenesis are known [40].

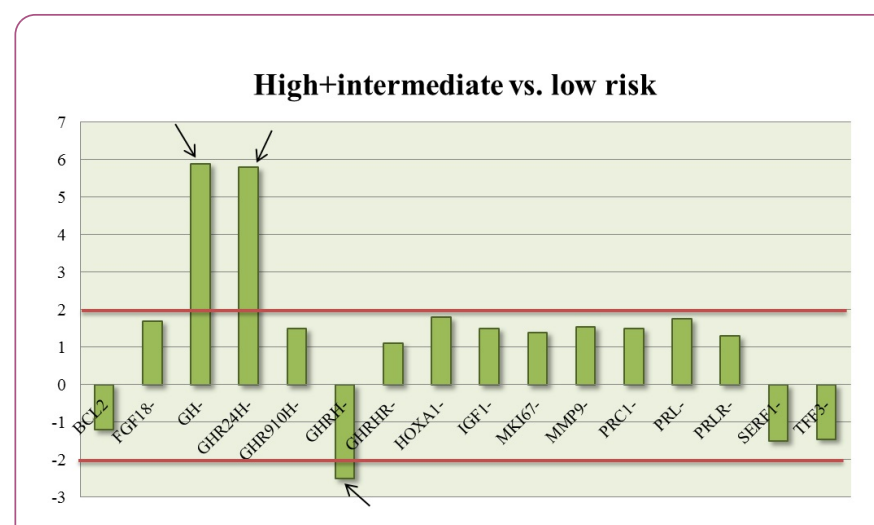

Figure 7 Profile of expression of the genes analyzed, considering the "High+Intermediate" risk group versus the "Low Risk" group. The red lines indicate the FC 2 cut-off.

These studies confirmed the evident anticancer efficacy of the inhibition of GH in breast cancer [41-44], as in many other non-neuroendocrine tumors, such as sarcomas [45], glioblastomas [46], neuroblastomas [47], cervico-facial tumors [48], esophageal tumors [49], non-small cell lung cancer [50], chronic lymphatic leukemia [51], and Hodgkin and Non Hodgkin lymphoma [52], by means of its physiological antidote, somatostatin and/or the analogue octreotide.

\section{Conclusion}

Our study confirmed that breast cancer with a high or intermediate risk of recurrence is generally characterized by over-expression of $\mathrm{GH}$ and its receptor (GHR). This scientific evidence provides the rationale for using somatostatin/ octreotide in combined oncotherapy, which act indifferently and equally pituitary and autocrine $\mathrm{GH}$, regardless of the presence of SSTR in the tumor cells. Since GH and correlated growth factors are over-expressed in all tumors, albeit to different extents, with activation of numerous proliferative and angiogenic signalling pathways, the negative regulation of $\mathrm{GH}$ by means of somatostatin has a logical explanation, and is extended to the correlated growth factors, as widely documented in the literature.

The generalized anticancer use of somatostatin can be explained since it antagonizes the common denominators and causal factors of all tumors, as well as the over-expression of the GH-GF correlated axis. In breast cancer, the close receptorial interaction of $\mathrm{GH}$ with prolactin and the functional interaction with estrogen lead, in a multitherapy setting, to synergic inhibition of GH-GF given by somatostatin/octreotide, of prolactin given by $\mathrm{D} 2 \mathrm{R}$ agonists, and estrogenic interaction by means of FSH-LH analogues and aromatase inhibitors, with decided progress in the treatment of these tumors. This strategy could be even reinforced by the cytostatic, differentiating, immunomodulating and trophic functions of other compounds, such as melatonin, solution of retinoids in vitamin E, vitamin D3 and vitamin C, (Di Bella Method), without toxic effects, instead significantly improving quality of life, objective response and survival compared to the same tumor stages of breast cancer treated with conventional oncological protocols. We draw attention to these concepts and these data with the intention of improving the prognosis of tumors in general and in the specific case of breast cancer, which still represents, throughout the world, the leading cause of death in women.

\section{Conflict of Interest}

The authors declare that there is no conflict of interest regarding the publication of this paper.

\section{References}

1. Laban C, Bustin SA, Jenkins PJ (2003) The GH-IGF-I axis and breast cancer. Trends Endocrinol Metab 14: 28-34.

2. Felice $\mathrm{DL}$, El-Shennawy L, Zhao S, Lantvit $\mathrm{DL}$, Shen $\mathrm{Q}$, et al. (2013) Growth hormone potentiates $17 \beta$-estradiol-dependent breast cancer cell proliferation independently of igf-i receptor signaling. Endocrinol 154: 3219-3227.

3. Tworoger S, Hankinson S (2006) Prolactin and breast cancer risk. Cancer Lett 243: 160-169.

4. Hynes NE, Watson CJ (2010) Mammary gland growth factors: Roles in normal development and in cancer. Cold Spring Harb Perspect Biol 2: a003186.

5. Zhu T, Goh EL, Graichen R, Ling L, Lobie PE (2001) Signal transduction via the growth hormone receptor. Cell Signal 13: 599-616.

6. Le Roith D, Bondy C, Yakar S, Liu JL, Butler A (2001) The somatomedin hypothesis: 2001. Endocr Rev 22: 53-74.

7. Goffin V, Kelly PA (1996) Prolactin and growth hormone receptors. Clin Endocrinol 45: 247-255.

8. Lincoln DT, Sinowatz F, Temmim-Baker L, Baker HI, Kolle S, et al. (1998) Growth hormone receptor expression in the nucleus and cytoplasm of normal and neoplastic cells. Histochem Cell Biol 109: 141-159.

9. Brooks AJ, Wooh JW, Tunny KA, Waters MJ (2008) Growth hormone receptor: Mechanism of action. Int J Biochem Cell Biol 40: 1984-1989. 
10. Lincoln DT, Sinowatz F, Baker L, Baker HI, Kolle S, et al. (1998) Growth hormone receptor expression in the nucleus and cytoplasm of normal and neoplastic cells. Histochem Cell Biol 109: 141-159.

11. Baumann G, Stolar MW, Amburn K, Barsano CP, DeVries BC (1986) A specific growth hormone-binding protein in human plasma: Initial characterization. J Clin Endocrinol Metab 62 134-141.

12. Herington AC, Ymer SI, Stevenson JL (1986) Affinity purification and structural characterization of a specific binding protein for human growth hormone in human serum. Biochem Biophys Res Commun 139: 150-155.

13. Edens A, Southard JN, Talamantes F (1994) Mouse growth hormone-binding protein and growth hormone receptor transcripts are produced from a single gene by alternative splicing. Endocrinology 135: 2802-2805.

14. Waters MJ, Spencer SA, Hamlin G, Henzel WJ, Wood WI (1990) Purification and partial sequence of the rabbit mammary gland prolactin receptor. Int J Biochem 22: 1089-1095.

15. Lowe WL, Roberts CT, Laskyt SR, Leroith D (1987) Differential expression of alternative $5^{\prime}$ untranslated regions in mRNAs encoding rat insulin-like growth factor I (growth hormone/ tissue-speciflc regulation). Biochemistry 84: 8946-8950.

16. Daughaday WH, Trivedi B (1987) Absence of serum growth hormone binding protein in patients with growth hormone receptor deficiency. Proc Natl Acad Sci 84: 4636-4640.

17. Hynes MA, Wyk JJ Van, Brooks PJ, D'Ercole AJ, Jansen M, et al. (1987) Growth hormone dependence of somatomedin-C/ Insulin-like growth factor-I and insulin-like growth factor-II messenger ribonucleic acids. Mol Endocrinol 1: 233-242.

18. Rabinovitch A, Quigley C, Rechler MM (1983) Growth hormone stimulates Islet B-cell replication in neonatal rat pancreatic monolayer cultures. Diabetes 32: 307-312.

19. Emerald BS, Chen Y, Zhu T, Zhu Z, Lee KO, et al. (2007) AlphaCP1 mediates stabilization of hTERT mRNA by autocrine human growth hormone. J Biol Chem 282: 680-690.

20. Dimri G, Band H, Band V (2005) Mammary epithelial cell transformation: Insights from cell culture and mouse models. Breast Cancer Res 7: 171

21. Stewart SA, Weinberg RA (2010) Telomeres: Cancer to human aging. Annu Rev Cell Dev Biol 22: 531-557.

22. Mukhina S, Mertani HC, Guo K, Lee KO, Gluckman PD, et al. (2004) From the cover: Phenotypic conversion of human mammary carcinoma cells by autocrine human growth hormone. Proc Natl Acad Sci 101: 15166-15171.

23. Arteaga CL, Osbornel CK (1989) Growth inhibition of human breast cancer cells in vitro with an antibody against the Type I somatomedin receptor 1. Cancer Res 49: 6237-6241.

24. Yee D, Paik S, Lebovic GS, Marcus RR, Favoni RE, et al. (1989) Analysis of Insulin-Like Growth Factor I Gene Expression in Malignancy: Evidence for a Paracrine Role in Human Breast Cancer. Mol Endocrinol 3: 509-517.

25. Hagg E, Asplund K, Holm J (19998) Acromegaly and multiple myeloma. Ann Intern Med 109: 437-438.

26. Ward HC, Halliday D, Sim AJ (1987) Protein and energy metabolism with biosynthetic human growth hormone after gastrointestinal surgery. Ann Surg 206: 56-61.
27. Ratner RE, Hare JW (1983) Association of acromegaly and chondrosarcoma. South Med J 76: 1181-1182.

28. Lawler J, Detmar M (2004) Tumor progression: The effects of thrombospondin-1 and -2. Int J Biochem Cell Biol 36: 1038-1045.

29. Kusano K, Tsutsumi Y, Dean J, Gavin M, Ma H, et al. (2007) Longterm stable expression of human growth hormone by rAAV promotes myocardial protection post-myocardial infarction. J Mol Cell Cardiol 42: 390-399.

30. Murphy LJ, Bell GI, Friesen HG (1987) Growth hormone stimulates sequential induction of c-myc and insulin-like growth factor I expression in vivo. Endocrinol 120: 1806-1812.

31. Gallego MI, Binart N, Robinson GW, Okagaki R, Coschigano KT, et al. (2001) Prolactin, growth hormone, and epidermal growth factor activate Stat5 in different compartments of mammary tissue and exert different and overlapping developmental effects. Dev Biol 229: 163-175.

32. Vacas E, Munoz-Moreno L, Valenzuela PL, Prieto JC, Schally AV, et al. (2016) Growth hormone-releasing hormone induced transactivation of epidermal growth factor receptor in human triple-negative breast cancer cells. Peptides 86: 153-161.

33. Brunet-Dunand SE, Vouyovitch C, Araneda S, Pandey V, Vidal LJP, et al. (2009) Autocrine human growth hormone promotes tumor angiogenesis in mammary carcinoma. Endocrinol 150: 1341-1352.

34. Lesniak MA, Hedo JA, Grunberger G, Marcus-Samuels B, Roth J, et al. (1987) Receptors for insulin and growth hormone on lymphoid cells. Methods Enzymol 150: 701-723.

35. Kozak RW, Haskell JF, Greenstein LA, Rechler MM, Waldmann TA, et al. (1987) Type I and II insulin-like growth factor receptors on human phytohemagglutinin-activated $\mathrm{T}$ lymphocytes. Cell Immunol 109: 318-333.

36. El Etreby MF, Mahrous AT (1979) Immunocytochemical technique for detection of prolactin (PRL) and growth hormone $(\mathrm{GH})$ in hyperplastic and neoplastic lesions of dog prostate and mammary gland. Histochemistry 64: 279-286.

37. Sinowatz F, Breipohl W, Waters MI, Lincoln D, Lobie PE, et al. (1991) Growth hormone receptor expression in the Dunning $R$ 3327 prostatic carcinoma of the rat. Prostate 19: 273-27.

38. Bengtsson BA, Eden S, Ernest I, Oden A, Sjogren B (1988) Epidemiology and long-term survival in acromegaly. A study of 166 cases diagnosed between 1955 and 1984. Acta Med Scand 223: 327-335.

39. Wu ZS, Yang K, Wan Y, Qian PX, Perry JK, et al. (2011) Tumor expression of human growth hormone and human prolactin predict a worse survival outcome in patients with mammary or endometrial carcinoma. J Clin Endocrinol Metab 96: e1619e1629.

40. Perry JK, Mohankumar KM, Emerald BS, Mertani HC, Lobie PE (2018) The contribution of growth hormone to mammary neoplasia. J Mammary Gland Biol Neoplasia 13: 131-145.

41. Di Bella G, Mascia F, Ricchi A, Colori B (2013) Evaluation of the safety and efficacy of the first-line treatment with somatostatin combined with melatonin, retinoids, vitamin D3 and low doses of cyclophosphamide in 20 cases of breast cancer: A preliminary report. Neuro Endocrinol Lett 34: 660-668.

42. Di Bella G (2008) Complete objective response to biological therapy of plurifocal breast carcinoma. Neuro Endocrinol Lett 29: 857-866. 
43. Di Bella G (2011) The Di Bella Method (DBM) improved survival, objective response and performance status in a retrospective observational clinical study on 122 cases of breast cancer. Neuro Endocrinol Lett 32: 751-762.

44. Di Bella G (2008) Complete objective response to biological therapy of plurifocal breast carcinoma. Neuro Endocrinol Lett 29: 857-866.

45. Di Bella G, Toscano R, Ricchi A, Colori B (2015) Congenital fibrosarcoma in complete remission with somatostatin, bromocriptine, retinoids, vitamin D3, vitamin E, vitamin C, melatonin, calcium, chondroitin sulfate associated with low doses of Cyclophosphamide in a 14-year Follow up. Neuro Endocrinol Lett 36: 725-733.

46. Di Bella G, Leci J, Ricchi A, Toscano R (2015) Recurrent glioblastoma multiforme (grade IV - WHO 2007): A case of complete objective response-concomitant administration of Somatostatin/Octreotide, Retinoids, Vit E, Vit D3, Vit C, Melatonin, D2 R agonists Di Bella Method Neuro Endocrinol Lett 36: 127-132.

47. Di Bella G, Colori B (2009) Complete objective response of neuroblastoma to biological treatment. Neuro Endocrinol Lett 30: 437-449.
48. Di Bella G, Colori B (2012) The Di Bella Method (DBM) improved survival, objective response and performance status in a retrospective observational clinical study on 23 tumours of the head and neck. Neuro Endocrinol Lett 33: 249-256.

49. Di Bella G, Madarena M (2009) Complete objective response of oesophageal squamocellular carcinoma to biological treatment. Neuro Endocrinol Lett 30: 312-321.

50. Norsa A, Martino V (2006) Somatostatin, retinoids, melatonin, vitamin $\mathrm{d}$, bromocriptine, and cyclophosphamide in advanced non-small-cell lung cancer patients with low performance status. Cancer Biother. Radiopharm 21: 68-73.

51. Di Bella G, Colori B, Mascia F (2012) The Di Bella Method (DBM) improved survival, objective response and performance status in a retrospective observational clinical study on 55 cases of lymphomas. Neuro Endocrinol Lett 33: 773-781.

52. Todisco M, Casaccia P, Rossi N (2001) Cyclophosphamide plus somatostatin, bromocriptin, retinoids, melatonin and ACTH in the treatment of low-grade non-Hodgkin's lymphomas at advanced stage: Results of a phase II trial. Cancer Biother Radiopharm 16: 171-177. 